Fecha de recepción: marzo 2020 Fecha de aceptación: abril 2020 Versión final: junio 2020

\section{El discurso político de Nayib Bukele en Twitter}

Julieta Grassetti ${ }^{(1)}$

Resumen: Nayib Bukele asumió como presidente de El Salvador el $1^{\circ}$ de junio de 2019. Con su triunfo se puso fin a la alternancia bipartidista entre el FMLN y ARENA, que primó por treinta años en el país. El presidente latinoamericano más joven es conocido como millennial debido a su presencia en las redes sociales. Bukele utiliza de manera continua estas herramientas como forma de comunicación política. Este artículo se propone indagar sobre la construcción del discurso político de Nayib Bukele en su cuenta de Twitter durante sus primeros cien días de gobierno. Se busca rastrear cómo fue construyendo un discurso desideologizado y ahistórico, en torno a la idea de eficiencia, la transparencia y la buena administración de los recursos del Estado.

Palabras clave: El Salvador - gobiernos empresarios - Bukele - discurso político - Twitter.

[Resúmenes en inglés y portugués en la página 224]

(1) Licenciada en Sociología (2014), Magíster en Estudios Sociales Latinoamericanos y Becaria Doctoral del CONICET, Facultad de Ciencias Sociales, Universidad de Buenos Aires. Investigadora del Grupo de Trabajo CLACSO “Élites empresariales, estado y dominación”. También participa del UBACyT "Estado, élites y grupos económicos en América Latina” dirigido por Inés Nercesian. Es miembro del equipo editorial de la Revista e-l@tina. Su área de interés es la Sociología Histórica de América Latina, en especial los estudios comparados sobre el cambio social en Centroamérica, con énfasis en las organizaciones político militares centroamericanas y los procesos de transformación a partidos políticos.

\title{
Introducción
}

Las elecciones generales del 3 de febrero de 2019 tuvieron como consecuencia, en El Salvador, el fin de treinta años de alternancia entre Alianza Republicana Nacionalista (ARENA) y el Frente Farabundo Martí para la Liberación Nacional (FMLN). El triunfo de Nayib Bukele con el 53\% inauguró en el país las primeras elecciones presidenciales donde las redes sociales fueron el principal canal de comunicación política.

Asimismo, su llegada al poder se enmarca un contexto de repliegue de los gobiernos 
posneoliberales que tuvieron lugar en la región a partir del inicio del siglo XXI. Por su trayectoria en el mundo privado, se alinea con al menos ocho países latinoamericanos que han sido gobernados por empresarios o figuras estrechamente vinculadas al mundo empresarial ${ }^{1}$.

Este escenario de giro conservador en la región presenta diferencias en cada caso nacional pero también elementos comunes. Estos presidentes empresarios se presentan como outsiders de la política, con discursos desidelogizados y ahistóricos que responden a una narrativa de eficiencia y transparencia vinculada a la buena gestión del Estado.

En este trabajo se analizan las publicaciones en la cuenta personal de Twitter de Nayib Bukele durante los primeros cien días de su gobierno (1 de junio de 2019 -momento en el que asume la presidencia- hasta el 9 de septiembre de 2019). La elección de Twitter para analizar su discurso político se debe a que, además de ser la primera red social creada por Bukele, es la que utiliza con mayor frecuencia. El objetivo de este artículo es dar cuenta de cómo el presidente salvadoreño fue construyendo un discurso político en línea con los gobiernos empresarios de la época en sus publicaciones.

El artículo comienza con el análisis de cómo llegó Bukele a ser un candidato presidenciable y su triunfo en una estructura bipartidista de larga data, en el marco de una crisis política regional y rupturas al interior del FLMN. Luego, se ofrece una breve aproximación teórica del vínculo entre los discursos políticos y las redes sociales. A continuación, se analizan los principales ejes discursivos presentes en las publicaciones de Twitter de Bukele durante los primeros cien días de su gobierno. Por último, se presentan reflexiones acerca de las novedades que presenta la figura de Bukele como presidente empresario en general y para la cultura política salvadoreña en particular.

\section{Fin del bipartidismo}

Hacia fines de la década de 1990 tuvo lugar una crisis política en América Latina que ocasionó una pérdida del rol central de los partidos como mediadores políticos privilegiados en la democracia representativa moderna. Francisco Durand (2010) sostiene que el neoliberalismo de los noventa en la región facilitó la llegada al poder de los empresarios a la política, a partir de la profunda modificación que se produjo en la estructura del poder económico.

Ansaldi (2017), siguiendo los planteos de Göran Therborn ([1978] 2016), refuerza la idea de que las burguesías latinoamericanas atravesaron una crisis de representación de los partidos tradicionales que han expresado y/o expresan sus intereses, por tanto hoy "están lanzadas a una ofensiva de creación de formatos de institucionalización capitalista" (p. 47). A partir del año 2000, al menos ocho países latinoamericanos han sido gobernados por empresarios o figuras estrechamente vinculadas al mundo empresarial ${ }^{2}$. El triunfo de $\mathrm{Na}$ yib Bukele en El Salvador el 3 de febrero de 2019 se inscribe en esta experiencia. Su gobierno presenta novedades a nivel nacional como el fin a la experiencia posneoliberal, la interrupción de treinta años de alternancia bipartidista y el uso de nuevas herramientas para instalar un discurso desideologizado y vinculado con la idea de una gestión eficiente. 
Luego de doce años de guerra civil, se llevó a cabo la firma de los Acuerdos de Paz en el año 1992 bajo el gobierno de Alfredo Cristiani (1989-1994). Por estos años se estableció un bipartidismo institucionalizado 3 (Mainwaring y Scully, 1997) que tuvo al FMLN y ARENA como las dos principales fuerzas opositoras que se enfrentaron desde ese momento hasta el triunfo de Bukele. El primero, como representante de la derecha salvadoreña gobernó desde el triunfo de Alfredo Cristiani en 1989 hasta 2009. El segundo, representando a distintos grupos de izquierda, lo hizo desde 2009 hasta el 2019.

Nayib Bukele es un empresario y publicista de 38 años que, antes de dedicarse a la política, fue dueño de la distribuidora Yamaha en el país y director de la empresa publicitaria de su padre, Obermet. Junto con su padre, Armando Bukele Kattán, se dedicó por doce años a realizar la publicidad política del FMLN.

La primera participación política de Bukele fue representando al FMLN, cuando logró el triunfo de la alcaldía de Nuevo Cuscatlán en 2012. Luego de esta experiencia, llegó a la alcaldía de San Salvador en 2015, nuevamente como candidato del mismo partido.

En 2017, el Tribunal de Ética del FMLN lo culpó de dividir al grupo y agredir verbalmente a una concejala de la alcaldía de San Salvador, y fue expulsado del partido. Detrás de esta razón se escondió una disputa al interior del partido. Bukele se posicionaba como posible candidato presidencial y encontró una fuerte resistencia de importantes cuadros históricos que proponían otras figuras presidenciales. La expulsión de Bukele reflejó las disputas al interior del FMLN y generó un alejamiento de algunos de sus militantes. Esto se sumó al descrédito que fue acumulando el partido debido al aumento de una serie de impuestos, la inseguridad, el desempleo y la percepción de corrupción.

Luego de ser expulsado del partido, Bukele anunció el 15 de octubre de 2017, a través de su canal de YouTube, la decisión de lanzar un movimiento para buscar la presidencia de la República de El Salvador en el año 2019. En este discurso Bukele apeló a una alegoría afirmando que:

Una golondrina sola no hace verano pero qué tal si somos un millón de golondrinas, qué tal si somos dos millones de golondrinas, qué tal si somos muchísimas más golondrinas de las que ellos se imaginan. Entonces sí haremos un verano. No nos van a poder detener porque millones de golondrinas no podrán ser detenidas (Bukele, 2017).

La crisis al interior del FMLN se expresó en las elecciones legislativas de 2018 en las que perdió su mayoría en la Asamblea Legislativa y, a partir de mayo de 2018, ninguna de las dos fuerzas principales contó con mayoría propia para imponer su agenda, y se vieron obligados a establecer alianzas con otros partidos políticos. Esta situación favoreció a las fuerzas de derecha, tanto la tradicional ARENA como aquella nucleada en Gran Alianza por la Unidad Nacional (GANA).

Ante la imposibilidad de inscribir su nuevo partido llamado Nuevas Ideas de cara a las presidenciales de 2019, debido a la negativa emitida por el Tribunal Supremo Electoral (TSE) por el incumplimiento de los tiempos de inscripción, Bukele se incorporó a la estructura de GANA. En las internas triunfó por amplio margen para ser su candidato en 2019. 
El 3 de febrero de 2019 logró imponerse Nayib Bukele con el 53\% votos frente al 31.72\% del candidato de ARENA, Carlos Calleja y el 14. 41\% del FMLN, Hugo Martínez.

A pesar de un fuerte abstencionismo en las elecciones nacionales ${ }^{4}$, el candidato de GANA logró más votos que los otros dos partidos juntos y ganó en los 14 departamentos del país.

\section{De publicista a presidente}

La llegada de un empresario a la presidencia no es una novedad para la historia salvadoreña. El primer empresario que llegó al poder por vía electoral fue el candidato de ARENA, Alfredo Cristiani (1989-1994), quien nació en el seno de una familia terrateniente vinculada a la producción y exportación del café. Al mismo tiempo, eran dueños de empresas farmacéuticas y algodoneras. El segundo caso es el de Elías Antonio Saca (20042009), empresario de origen árabe que se destacó en el rubro radiofónico. Este último llegó al poder a través de GANA, el mismo partido por el que obtuvo su victoria Bukele. A diferencia de estos dos casos, Bukele desde un comienzo buscó romper con los partidos tradicionales presentándose como "lo nuevo" como el "cambio". De esta manera, pretende instalar un discurso desideologizado que termine con la dicotomía izquierdaderecha. Este mensaje "desdibuja la conflictividad social en términos clasistas" (Ansaldi, 2017). A tono con las derechas en la región, presenta novedades en el tipo de campaña y en la incorporación de otros canales de comunicación.

Bukele es, con 38 años, el presidente latinoamericano más joven y es conocido como el presidente millennial debido a la presencia que tiene en las redes sociales. Las principales medidas adoptadas por su gobierno, así como las "órdenes" dirigidas a sus ministros, fueron comunicadas a través de mensajes de Twitter. No asistió a los debates presidenciales ni dio conferencias de prensa hasta que ganó las elecciones. Una vez en el gobierno, no dio cadenas nacionales hasta casi un mes y medio después de asumir. En aquellos casos donde necesitó más tiempo para comunicar alguna medida, recurrió a Facebook Live. Bukele logró limpiar la imagen del partido de derecha GANA, caracterizado por su color naranja y vinculado con casos de corrupción y narcotráfico ${ }^{5}$. Para eso cambió su color y su emblema. En la papeleta de votación (no aparece la imagen de los candidatos sino de los partidos), se presentó una imagen renovada donde sólo aparecía una bandera color cian y una golondrina sin figurar en ella las siglas del partido.

Desde GANA, se presentó como un outsider de la política, sin desconocer sus logros como alcalde, pero instalándose como la "opción de cambio" frente a los candidatos de los partidos tradicionales. Como alcalde de San Salvador llevó a cabo la restauración y renovación de determinados espacios urbanos, entre los que se destacó el Centro Histórico. Estas acciones fueron reivindicadas y le permitieron "generar simpatías con la población basado en un discurso que buscaba vender la idea de la "eficiencia" por encima del contenido político e ideológico" (Saravia y Canteros, 2019).

Bukele buscó capitalizar el descontento y la desconfianza social hacia la clase política tradicional persuadiendo al electorado a través de sus redes sociales, de que era necesario un cambio para acabar con la corrupción, con la clase política anquilosada en el poder y 
la necesidad de apostar a dirigentes que creen futuro para el país. Se presentó entonces como un hombre sin ideología política. Durante su campaña se encargó de difundir su slogan "El dinero alcanza cuando nadie roba" viralizando el hashtag \#DevuelvanLoRobado, en reclamo a funcionarios del gobierno tanto del FMLN como de ARENA.

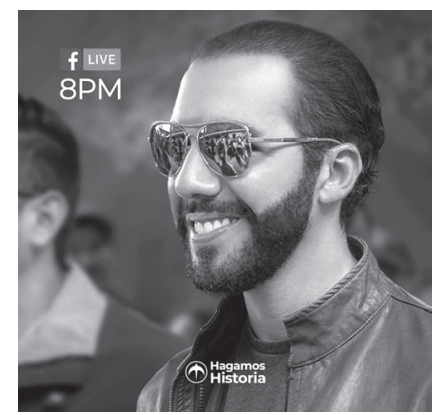

Figura 1. Bukele, el presidente millennial de El Salvador. Fuente: Nayib Bukele. (Diciembre de 2018). Twitter. Disponible en: https://twitter.com/nayibbukele/ status/1074465878723477504

El candidato a presidente se presentó con una imagen juvenil donde destacaba su campera de cuero y lentes de sol, sacándose selfies y andando en patineta. Bukele buscó atraer especialmente el voto joven ${ }^{6}$. Por esta razón, explotó al máximo su presencia en las redes sociales aprovechando sus conocimientos en el mundo del marketing y la publicidad. Los jóvenes, no vivieron la guerra civil o eran pequeños, por eso durante su campaña apeló a dar vuelta la página de la posguerra, dejar atrás a los partidos tradicionales e instalar un gobierno para las generaciones futuras.

De este modo, fue construyendo un discurso sin definiciones ideológicas tajantes que le permitió posicionarse como un candidato que mira hacia el futuro. En el acto donde se proclamó ganador en la plaza Morazán, Bukele antes de hacer cualquier cosa, se sacó y posteó una selfie. Más tarde, subió al escenario con la canción de Coldplay Viva la vida de fondo, acompañado por papel picado mientras la gente lo vitoreaba y, al grito de "sí se pudo", esperaba su mensaje.

No se puede evitar trazar un paralelismo con el acto de asunción de Macri. Vommaro (2014) analizando este caso afirma que "el uso de globos, de banderines de colores, de coreografías festivas (el flashmob), de cotillón de casamiento o pelucas y disfraces, se liga precisamente a esta celebración de la vida plácida en una ciudad estetizada, sin violencia ni conflicto" (p.69).

El conflicto fue un gran ausente tanto en este discurso de Bukele como en el acto de asunción a la presidencia, si bien por razones ligadas a la historia de El Salvador, no pudo evitar mencionar la violencia. En su discurso afirmaba que ese 3 de febrero de 2019:

No elegimos un presidente, hoy pasamos la página del bipartidismo, pasamos la página de la posguerra y le dijimos a Arena y al Frente, nunca más. Nunca más nuestro país volverá a ver un gobierno de ARENA o del Frente. Eso quedó 
en nuestra historia. Quedó en nuestro pasado. Se respeta como nuestra historia, como pasado, pero no pueden acompañarnos al futuro (MBN Digital, 2019).

Con estas frases pretende borrar la historia y el pasado del país en pos de un futuro ahistórico y desideologizado. Esta idea se reforzó el día que asumió su mandato el $1^{\circ}$ de junio de 2019 "Hoy estoy aquí, con ustedes, este día inicia el nuevo gobierno de El Salvador. Este día inicia la nueva historia que vamos a escribir juntos" (El Faro, 2019).

Como afirma Nathalie Goldwaser respecto del caso argentino:

La eliminación a las referencias históricas no sólo es una cuestión de ignorancia y desinterés por nuestra herencia cultural y política; es también una estrategia ideológica, porque generar olvido y denostar el pasado reciente permite reinstalar un modelo de vaciamiento material, simbólico y discursivo a través de palabras fallidas que finalmente permitieron atraer a los votantes (ahora devenidos en público) que hicieron posible revivir los muertos de la felicidad (2016).

Al tiempo que borra el pasado, en su discurso desdibuja el conflicto y la división de clases apelando a un "nosotros" como un todo indiscriminable y homogéneo.

Aquí, el veterano de guerra y el ex combatiente del FMLN es hermano con el otro. El rico es hermano del pobre. El de la zona urbana es hermano del de la zona rural. El anciano es hermano del joven y el hombre es hermano de la mujer (MBN Digital, 2019).

Nuevamente, al igual que en el caso argentino, la falta de compromiso con el pasado, la reivindicación de un mundo sin conflictos, contribuyó a interpelar a aquellos que se oponía a los partidos tradicionales, principalmente al FMLN, que fue el que más votos perdió en estas elecciones ${ }^{7}$.

De ahora en adelante, el país que vamos a construir, lo vamos a construir entre todos. Con la responsabilidad personal e individual que eso implica. Porque el futuro que vamos a construir hoy, no depende de derechas ni de izquierdas, no depende de ideologías fracasadas de los ochentas, no depende de los bandos de la guerra (MBN Digital, 2019).

En esta frase, además de buscar posicionarse como un partido sin ideología y ahistórico, reivindica la idea del voluntarismo e individualismo proveniente del mundo empresarial al que se suma el éxito del emprendedor (Vommaro, 2014). El día que asumió volvió sobre esta idea con una apología biologicista en la que comparó al país con un niño enfermo.

Nos toca ahora a todos cuidarlo. Nos toca ahora a todos tomar un poco de medicina amarga. Nos toca ahora a todos sufrir un poco. Nos toca ahora a todos tener un poco de dolor. Asumir nuestra responsabilidad. Y todos, como hermanos, sacar adelante a ese niño que es nuestra familia. Que es nuestro país, es 
El Salvador. (...) Cada uno de nosotros tiene una responsabilidad individual (El Faro, 2019).

El cambio depende de cada ciudadano, que es responsable y debe esforzarse por mejorar el país. "Nos vamos a ayudar entre todos porque somos hermanos". No aparece acá el Estado como mediador y responsable sino que apela directamente al individualismo.

\section{El discurso político en 280 caracteres}

La política contemporánea está atravesada por la utilización de los medios masivos de comunicación clásicos a los que se sumaron las redes sociales como Facebook, Instagram y Twitter. Los candidatos se vieron obligados a generar nuevos discursos políticos y modos de hacer campaña incorporando estos medios. La decisión de analizar Twitter tiene que ver con diferentes motivos. En esta red social que se conoce como microblogging el usuario escribe entradas que no deben exceder los 280 caracteres. En comparación con otras redes sociales, Twitter permite

Contar con internautas seguidores a los cuáles no seguir, posibilita el funcionamiento de la red social de un modo cercano a la lógica de uno a muchos, central en los medios masivos de comunicación. De este modo, en el caso de los enunciadores políticos (al igual que las figuras públicas), se generan miles de seguidores y muchos menos usuarios a los que el candidato sigue (Slimovich, 2016).

Es decir, que a comparación de Facebook, Twitter obliga a adaptar el mensaje político a esa estructura limitada, pero permite tener mayor cantidad de lectores ${ }^{8}$. Por lo tanto, este formato de blog es el más utilizado por los políticos para difundir sus campañas y los actos de gobierno, así como para debatir entre distintas fuerzas sociales. Sin desmerecer el uso de otras redes sociales, Twitter resulta la más utilizada para la políticaw.

En el caso del presidente de El Salvador, si bien tiene una fuerte participación en todas las redes sociales, Twitter es la que más utiliza para expresar opiniones, decisiones y mensajes. Además, las elecciones de 2019 fueron las primeras presidenciales en las que "las redes sociales se impusieron como el principal canal de comunicación política" (Girón y Marroquín, 2019).

Su cuenta de Twitter fue creada en 2009 y tiene en la actualidad un millón doscientos mil seguidores. En el caso de Facebook, este número asciende al doble, su página creada en 2011 llega a la cifra de dos millones ciento noventa y ocho mil personas. Sin embargo, su mayor actividad la presenta en Twitter. En sus primeros días de gobierno llegó a postear más de 20 tuits en un día, mientras que en Facebook sus posteos no son diarios y muchas veces repiten la información presente en la red social del pajarito. 


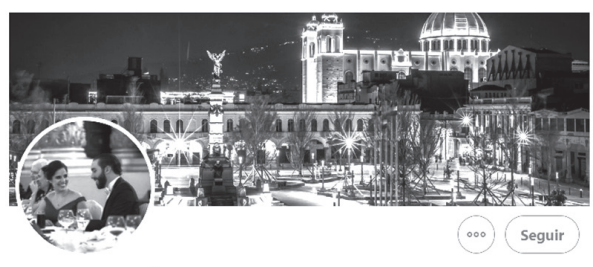

Nayib Bukele

@nayibbukele

El Presidente más genial del mundo mundial.

() El Salvador $\mathcal{Q}$ presidencia.gob.sv $Q$ Fecha de nacimiento: 24 de julio

Se unió el febrero de 2009

561 Siguiendo $1 \mathrm{M}$ seguidores
Figura 2. Perfil de Twitter de Nayib Bukele. Fuente: Biografía de Nayib Bukele. (Junio de 2019). Twitter. Disponible en: https://twitter.com/nayibbukele

Para realizar el análisis de sus tuits se retoman los trabajos de Ana Slimovich (2014, 2016, 2017a, 2017b, 2019) donde la autora combina la metodología de análisis del discurso y sociosemiótica de Verón (1987a), incorporando herramientas de la teoría de la circulación hipermediática (Carlón, 2015). Carlón en su entrevista con Fraticelli (2019), hace una lectura del concepto clásico de sociedad mediatizada de Verón (1998) y sostiene que:

Una sociedad mediatizada, en cambio, es aquella en la que las lógicas culturales empiezan a organizarse en función de las lógicas de los medios. Se considera que los medios ya no actúan bajo una lógica representacional, sino que son productores de sentido. Es la época en la que se discute la construcción del acontecimiento.

En las sociedades mediatizadas, "los medios masivos se asumen como capaces de construir la realidad. Las prácticas políticas, entonces, están estructuradas en función de las lógicas de los medios masivos" (Slimovich, 2017a). En las sociedades hipermediatizadas (Carlón, 2015), se desarrollan fenómenos de relación entre el sistema de medios masivos y el sistema de medios con base en Internet. Las prácticas políticas, por ende, se ven influidas por estas nuevas condiciones de la circulación de los discursos.

Para relevar los principales ejes del discurso político de Nayib Bukele en Twitter, se analizaron las publicaciones de su cuenta personal desde el 1 de junio de 2019 -momento en el que asume la presidencia- hasta el 9 de septiembre de 2019. Se toma este período por abarcar los primeros cien días de su gobierno ${ }^{10}$. El corpus total de tuits utilizados para el artículo fue de $175^{11}$. Para su análisis no se priorizó una lectura cuantitativa que diera cuenta de la cantidad de publicaciones por día y de cómo éstas variaron en el tiempo, sino que se desarrolló una lectura cualitativa. Por lo tanto, se realizó un análisis de discurso de las publicaciones en Twitter del presidente salvadoreño buscando rastrear elementos que permitieran evidenciar la presencia de: un discurso desideologizado y ahistórico; la teatralización de su vida privada; la celibrificación de su imagen; y características de los principios de gobierno abierto (gestión eficiente, pragmatismo y transparencia). 


\section{Los tuits del presidente "más genial del mundo mundial"}

El perfil de Bukele en Twitter se caracteriza por una foto del presidente sonriendo con la banda presidencial y una leyenda que lo describe como "el presidente más genial del mundo mundial". Su biografía cambió el 15 de agosto de 2019 cuando fue padre. A partir de ese momento, su foto de perfil lo muestra en una cena con su esposa y su descripción es: "papá de Layla".

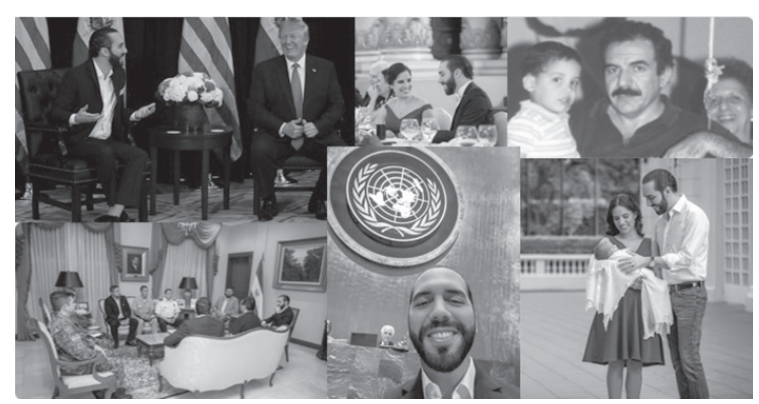

Figura 3. Collage teatralización de la vida privada. Fuente: Elaboración propia en base a las publicaciones de Nayib Bukele.

De modo que el discurso político de Bukele está atravesado constantemente por motivos temáticos vinculados a lo biográfico y a lo íntimo. Al igual que en el análisis que hace Slimovich (2017b) sobre el discurso de Macri, en el caso salvadoreño hay una teatralización de la vida privada: una puesta en escena de la subjetividad en su muro (que se replica en otras redes sociales) donde Bukele se muestra en situaciones de la vida cotidiana y donde se destaca primero como esposo y, después, como padre.

Por lo tanto, en el discurso de Bukele en las redes existe un entrecruzamiento permanente entre lo público y lo privado. Entre ellas encontramos una foto de niño con su padre en la que le dice que lo extraña, que le gustaría que viera lo que están haciendo por su país y en donde le cuenta que va a ser abuelo. A estas se suman referencias al embarazo de su esposa, salidas con ella y las primeras fotos de Layla. Esta idea de humanizar la imagen del candidato y/o presidente parece estar presente en varios de los casos de los gobiernos empresarios en la región.

En su análisis sobre los contenidos publicados por cinco candidatos a la presidencia del Gobierno de España en Instagram, Quevedo-Redondo y Portales-Oliva (2017) sostienen como una de sus hipótesis que:

El político instagramer compagina las imágenes profesionales con otras de tipo personal, dando lugar a un proceso de celebrificación que persigue activar la empatía de un target joven con un estilo más ligero e informal que el acostumbrado en medios tradicionales (p. 918). 
De esta manera, Bukele atraviesa este proceso de celebrificación que le permite apelar al votante joven y al que dirige principalmente su discurso de pasar de página la posguerra.

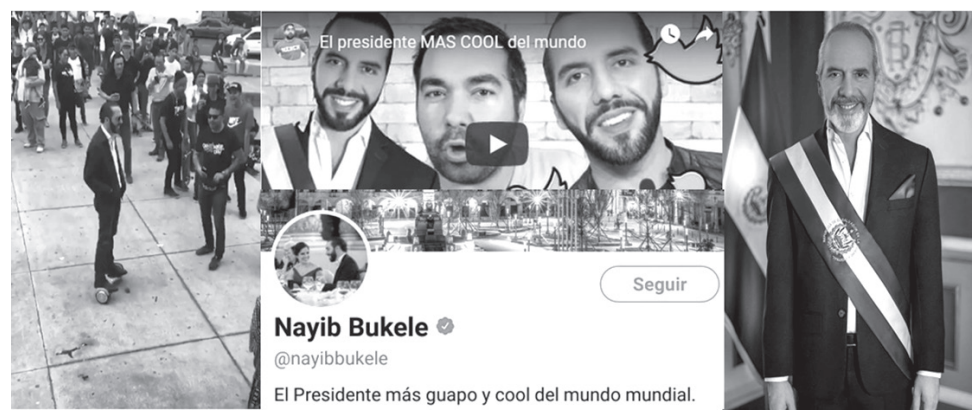

Figura 4. El presidente cool. Fuente: Elaboración propia en base a las publicaciones de Nayib Bukele.

Estos posteos, junto con aquellos en los que utiliza un lenguaje o frases apelando a los jóvenes, son los que tienen mayor cantidad de "me gusta". En segundo lugar se ubican los vinculados a denunciar la corrupción. En algunos casos llegan a los $55.8 \mathrm{~K}$ o a $66.7 \mathrm{~K}$, por ejemplo, cuando posteó "se les ordena a todos darle like y así ser el Presidente de Twitter" o cuando subió un resumen de un influencer mexicano donde definió "oficialmente soy el presidente más cool del mundo". Bukele se muestra cercano a la juventud en el uso de las redes y en el lenguaje que emplea y al mismo tiempo establece un vínculo con ellos retwitteando videos, saludándolos por sus cumpleaños y “ordenándoles” sacar más de 8 en sus exámenes.

Según los datos presentados en el estudio de Girón y Marroquín (2019), la Encuesta de Hogares de Propósitos Múltiples 2017 señala que únicamente 1.8 millones de salvadoreños tienen acceso a Internet, lo que equivale a un 34\% de la población. Del total, según datos de la encuestadora LPG, sólo el $10.7 \%$ de la población mayor de 18 años tiene Twitter en El Salvador ${ }^{12}$.

Otro de los datos que arrojan las últimas elecciones presidenciales según el registro del Tribunal Supremo Electoral, no hubo un aumento en la participación de los jóvenes de entre 18 y 29 años respecto de las elecciones de 2014. La diferencia entre 2019 para el grupo etario 18-23 años y 24-29 años y la primera vuelta de 2014 no llega al 1\%. Donde sí hubo una baja que explica la disminución porcentual en la participación a nivel nacional es en el grupo de 30 años o más.

Estos datos nos llevan a indagar cómo fue construyendo su discurso político el presidente millennial y principalmente a quiénes estuvo dirigido.

La presencia de elementos privados de la vida de Bukele aparece alternada con la designación del nuevo gabinete, con los relatos sobre los primeros viajes internacionales del presidente a Asia, con despidos a funcionarios y otras actividades el gobierno. 
Otro de los rasgos significativos del discurso político de Bukele en Twitter es que durante estos primeros tres meses potenció los principios del Gobierno Abierto ${ }^{13}$ vinculados a la gestión eficiente, la transparencia y la lucha contra la corrupción. La gestión eficiente se presenta por encima de cualquier contenido político e ideológico.

El domingo 2 de junio de 2019 disolvió, a través de Twitter, cinco secretarías: inclusión social, gobernabilidad, vulnerabilidad, transparencia y técnica. Dicho por el propio presidente esto fue hecho en "aras de hacer más eficiente el Estado". En 280 caracteres eliminó unos 600 cargos públicos y, según indicaba, el Estado pasó a “ahorrarse 15 millones de dólares en salarios por año".

En cuanto al discurso de la lucha contra la corrupción y el nepotismo, Bukele recurrió nuevamente a Twitter para despedir a decenas de funcionarios por su parentesco con integrantes del FMLN. La particularidad que asumió la narrativa de estos despidos fue que para realizarlos utilizó la frase "se le ordena". Por lo tanto, a través de la red social "ordenaba" arrobando la cuenta personal del ministro correspondiente para solicitarle la baja de algún funcionario.

Este estilo vertical y autoritario que utilizó Bukele para efectuar e informar el despido de funcionarios responde a la misma búsqueda de mostrar una gestión eficiente, pragmática y transparente. Sus ministros, competían por responder rápidamente a este pedido y de la forma más creativa "sí, mi presidente"; "ahorita mismo"; "su orden será ejecutada"; "de inmediato, señor presidente"; "Gracias, mil gracias, cuente conmigo".

Este modismo de dar órdenes obtuvo gran aceptación entre sus seguidores. Las palabras "se le ordena" fueron tendencia en Twitter y hasta fue replicada por fuera de las redes: una empresa de gaseosas sacó un anuncio donde figuraba la la frase: "se le ordena a los salvadoreños disfrutar lo nuestro".

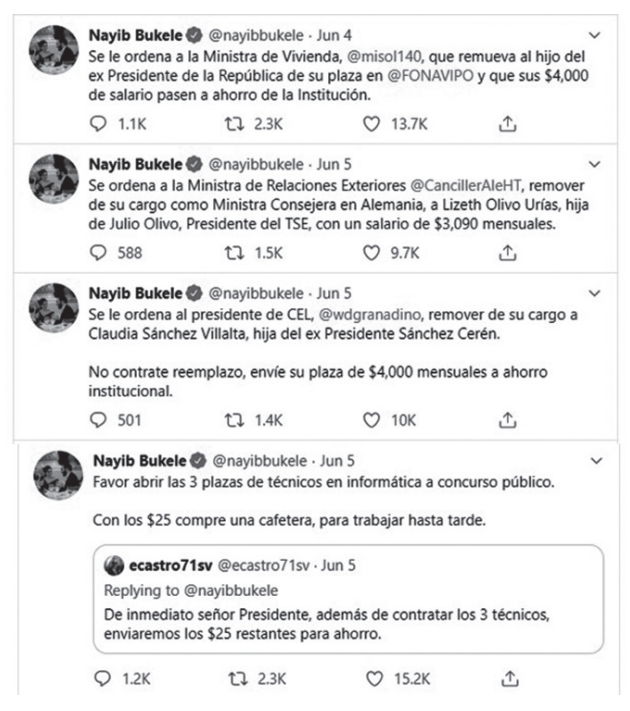

Figura 5. Se le ordena. Fuente: Elaboración propia en base a las publicaciones de Nayib Bukele. 
Al mismo tiempo, buscó reforzar la idea detrás del slogan de campaña de que "el dinero alcanza cuando nadie roba". De estos, hay muchos ejemplos donde Bukele ordena destinar los salarios de los funcionarios despedidos hacia "ahorro institucional". La "buena" administración permitió que con el sueldo del Director de Innovación Tecnológica e Informática del Gobierno de El Salvador se contratara a tres técnicos informáticos. Al mismo tiempo, con el dinero sobrante ordenó que se compra una cafetera para "trabajar hasta tarde".

Aquí además, aparece otro elemento que se vincula con un ethos empresarial de meritocracia y entrega completa en tiempo y sacrificio por la "empresa", que en este caso se traduce en ver salir al país adelante. Esta idea ya estaba presente en los discursos de triunfo y asunción, pero se refuerza en sus tuits. El propio Bukele da el ejemplo y publica a la madrugada "Ya habrá tiempo para dormir... Ahora hay un país que arreglar", "Dicen que necesito ir a dormir porque me necesitan despierto mañana domingo... Pero si ya es domingo" "24/7”. Asimismo, se dirige a sus funcionarios, “¿Niños cruzando ese puente? Quiero una solución de inmediato" a lo que el funcionario responde que se encargarán de inmediato. "Nuestro país hereda un sistema en ruinas... quiero un plan completo en 10 días" "Señor presidente haremos historia, vamos a modernizar la gestión pública para cumplirle a nuestro pueblo". "Al que madruga, Dios le ayuda. Ministros, a trabajar, que El Salvador no va a cambiar por sí solo".

De esta manera, Bukele da cuenta de la eficiencia y velocidad con que el Estado resuelve los problemas de la gente. Muchas veces, las exigencias de Bukele hacia sus ministros y/o alcaldes, son en respuesta a las demandas de quienes lo siguen y reclaman a través de Twitter.

\section{Cadena nacional: cien días de gobierno}

Las principales acciones de gobierno en estos cien días estuvieron reflejadas en dos ejes: la lucha por la seguridad y contra la corrupción. Respecto de la primera, tomó predominancia en su Twitter a partir del 20 de junio, cuando se puso en marcha el Plan Control Territorial fase I. Este plan se enfocó en tres áreas principales: control de los centros penales, interrupción del financiamiento al crimen organizado y el fortalecimiento de los cuerpos de seguridad.

En su programa de campaña, expresado en el Plan Cuscatlán, se criticaban las políticas de "mano dura" de los gobiernos anteriores y se proponía controlar los homicidios entendiendo al crimen como un "problema social surgido de la falta de oportunidades y de la pobreza”. Sin embargo, el Plan Control Territorial no incluye, hasta el momento, políticas de prevención, reinserción, capacitación laboral y educación. Por el contrario, pareciera alinearse con la "mano dura". En palabras del propio Bukele, "Malditos, vamos tras ellos, no se van a escapar. Y no me salgan con ser suaves, les va a caer todo el peso de la ley". El gobierno lleva un discurso de implacabilidad y eficiencia frente a la inseguridad, que es una de las mayores demandas de la población. "Las maras están queriendo obligarnos a quitar la emergencia máxima en los centros penales. Al igual que algunos jueces. Sepan 
que estas acciones sólo lograrán lo contrario. Si no bajan los homicidios, nadie ve un rayito de sol ¿Está claro o se los explicamos con manzanas?”.

Como parte del plan se incorporaron tres mil nuevos soldados para "combatir la delincuencia" junto con más personal policial, la ubicación de cámaras de vigilancia en distintos puntos de las grandes ciudades, la mejora en calzado y uniformes de los oficiales y un bono extra, entre otras cosas.

El control de territorios y el freno a las maras a través de distintos dispositivos, le permitió a Bukele mostrar cómo el éxito de este plan llevó a reducir la tasa de homicidios a nivel nacional. El Salvador es uno de los países con la mayor tasa de violencia en el mundo con un promedio de cinco homicidios diarios y más de 150 muertes por mes. Bukele publicó a diario el número de homicidios que fue bajando hasta que el 31 de julio llegó, por primera vez, a ningún registro de homicidios.

Al mismo tiempo que el discurso de la mano dura, reaparece la idea eficiencia en la que el gobierno demuestra que sus acciones tienen consecuencias y resultados inmediatos. "Por cierto, llevamos 2 días con 2 homicidios diarios. En el Gobierno del partido por el que votaste, eran 11 al día”. La eficiencia y buena administración de los recursos destinados a financiar a las Fuerzas Armadas y a la policía, también le permiten al Estado ahorrar dinero "implementaremos un plan para que los reos empiecen a producir sus propios alimentos, ahorrándole al Estado decenas de millones de dólares". Por lo tanto, queda claro cómo la delincuencia pasa de entenderse como un problema social a ser resuelto por la gestión.

En la cadena nacional que dio con motivo de los cien días de su gobierno, Bukele resumió algunos puntos a destacar de su gobierno entre los que se encontraban mejoras en el plano de la "seguridad, la salud y el bienestar social". Bajo el hashtag \#YEstoApenasEmpieza compartió en Twitter su discurso planteando una pregunta nodal “¿De qué nos serviría tener seguridad y bienestar social si seguimos sufriendo el flagelo de la corrupción?”.

En este marco, presentó la creación de la Comisión Internacional Contra la Impunidad de El Salvador (CICIES), con dirección de la OEA. Esta comisión anticorrupción imita la iniciativa contra la impunidad implementada en Guatemala entre 2006 y 2019. La CICIES se incorpora a la narrativa de la búsqueda de la transparencia.

Tenemos que empezar de cero. Porque desde el primer día de nuestro gobierno encontramos un sistema que está diseñado para que la incompetencia sea lo normal. Sabíamos que íbamos a encontrar corrupción, pero no sabíamos que tanta. Tampoco sabíamos que encontraríamos un trabajo gubernamental estancado. Que la cultura del mínimo esfuerzo predominaba en casi todos los ministerios y autónomas. Que teníamos un aparato estatal totalmente obsoleto (Bukele, 2019).

El discurso vinculado a la eficiencia, la buena gestión y la transparencia en esta cadena nacional devela los objetivos que están por detrás de "la lucha contra la corrupción". Bukele afirma que la instalación de la CICIES en el día 98 de su gobierno con apoyo de la OEA y de la comunidad internacional servirá para "prevenir, investigar y castigar actos de corrupción”. Este organismo será “independiente, neutral y transparente”. Este 
gobierno "transparente, con objetivos claros, que busque el bienestar social para todo El Salvador" que propone Bukele, aumentará la confianza para favorecer "la inversión de la empresa privada y capitales internacionales".

Esto permitió que en los primeros cien días de gobierno, El Salvador reestableciera "relaciones con nuestro mayor aliado internacional”. Según afirma el propio presidente, esa relación "está en su mejor momento en décadas. Altos funcionarios de los Estados Unidos nos han visitado para crear acuerdos que nos ayuden al desarrollo, que nos ayuden a construir este proyecto de país al que le estamos apostando". Además de permitir recuperar la confianza de Estados Unidos para el "pulgarcito" de Centroamérica, la lucha contra la corrupción favorecería que los más de tres millones de salvadoreños que viven en el exterior recuperen su confianza en el país. Las remesas ingresadas a El Salvador por los familiares representan cerca de un 16\% del PBI, cinco mil cuatrocientos millones de dólares, según el presidente, y algunos estarían dispuestos a invertir en el país.

\section{Conclusiones: ¿Qué novedad presenta Nayib Bukele en El Salvador?}

El gobierno de un presidente que se dedicaba al ámbito privado no presenta una novedad para El Salvador. Los ya mencionados casos de Cristiani y Saca como representantes de ARENA el primero y GANA el segundo, marcan un antecedente en este sentido. Tampoco lo es el uso de redes sociales en la práctica política. Una investigación sobre el uso de las páginas de Facebook y de Twitter en la campaña electoral a alcaldes en 2012 de Norman Quijano, Óscar Ortiz y Will Salgado da cuenta de la existencia y relevancia de este fenómeno en El Salvador (Hernández Guzmán, 2013).

Sin embargo, sí es una novedad que el uso de las redes sociales sea el principal canal de comunicación política. También lo es que el principal eje del discurso político esté vinculado a la buena gestión, la transparencia y la eficiencia. Además lo es que el triunfo de un empresario se de en un contexto en el que al menos ocho países latinoamericanos han sido gobernados por empresarios o figuras estrechamente vinculadas al mundo empresarial. Y lo es, además, que se haya construido como candidato presidenciable un empresario que venía del ámbito privado pero que tiene una larga trayectoria en uno de los partidos políticos tradicionales. Por último, es novedad que un gobierno empresario ponga fin a 10 años de experiencia posneoliberal en el país, ya que lo que permitió que Bukele se transformara de publicista a presidente, en primera instancia, fue la ruptura al interior del FMLN.

El análisis del discurso político de Nayib Bukele en sus primeros cien días de gobierno en Twitter refleja un nuevo modo de hacer política donde prima un lenguaje desideologizado y ahistórico. Desde un primer momento Bukele se posiciona como la opción de cambio frente al fracaso de la política de los partidos tradicionales. Lo hace con un lenguaje donde se desdibuja la historia, la división de clases y la política se convierte en mera gestión.

Lo interesante de esta estrategia es que la inauguración de un puente o la repavimentación de una ruta conviven con el anuncio del nacimiento de su primera hija, Layla. La 
celebrificación (Quevedo-Redondo y Portalés-Oliva, 2017) y la teatralización de su vida privada le permiten activar la empatía de los jóvenes y posicionarse como un hombre común. De esta manera apela a los jóvenes (de 18-30 años) que no vivieron la guerra civil y les propone pasar la página de la posguerra.

Si bien es cierto que Bukele obtuvo, en gran parte, apoyo de la juventud, los datos presentados por Girón y Marroquín (2019), los de la encuestadora LPG y los del Tribunal Supremo electoral, demuestran que no hubo un aumento significativo de la participación de jóvenes en las elecciones de 2019 y que el porcentaje de salvadoreños que tiene acceso a Internet y utiliza Twitter es bajo. Esto lleva a cuestionarse, entonces, ¿a quién va dirigido el discurso político de Bukele?

El presidente millennial fue construyendo un discurso sin definiciones ideológicas tajantes, lo que le permitió posicionarse como un candidato que mira hacia el futuro. Un discurso en el que se propuso pasar la página de la posguerra y borrar el pasado para "escribir una nueva historia". Esta nueva historia es reescrita en el discurso de Bukele a través de una narrativa de eficiencia y transparencia vinculada con la buena gestión del Estado. Entonces, ¿qué hay detrás de la idea de mostrar este Estado eficiente, transparente y sin corrupción?

Con motivo de hacer un balance de sus primeros cien días de su gobierno, Bukele anunció la creación de Comisión Internacional Contra la Impunidad de El Salvador (CICIES), con dirección de la Organización de Estados Americanos (OEA). Este organismo que será "independiente, neutral y transparente", se alinea con el propósito del gobierno de posicionarse como "transparente, con objetivos claros, que busque el bienestar social para todo El Salvador" y se orienta a incrementar la confianza en el país para favorecer "la inversión de la empresa privada y capitales internacionales" (Bukele, 2019).

En este anuncio el presidente explícitamente vinculó los elementos del Gobierno Abierto con la intención de asegurar la seguridad jurídica para el país que garantice la inversión de la empresa privada y capitales internacionales, para lo cual es necesario cambiar la percepción del país en el exterior. Es necesario mostrarse como un país "confiable y transparente" para lograr que las relaciones con Estados Unidos estén en su mejor momento en décadas, como anunciaba Bukele el 9 de septiembre de 2019. En este último discurso, el "hombre sin ideología" devela que no existe tal afirmación y que la transparencia, la eficiencia y la buena administración del Estado están buscando favorecer la inversión de las empresas privadas y el ingreso de capitales norteamericanos.

Bukele fue puliendo esta imagen a través de su discurso de Twitter que se presenta como apolítico y refleja la buena gestión bajo la premisa de que generar confianza es la base para el progreso del país. De esta manera, en su discurso les está hablando a los Estados Unidos para que vuelvan a tener confianza e inviertan y financien proyectos en El Salvador y, al mismo tiempo, a los empresarios salvadoreños que construyeron sus riquezas en el exterior en los años ochenta. Estos empresarios que se fueron del país durante la guerra civil (1981-1992) y que aportan un 16\% al PBI con el envío mensual de remesas a sus familiares. Estos empresarios que son los que Bukele afirma que están recuperando la confianza, estos "más de 3 millones de salvadoreños que viven en el exterior y extrañan su hogar" que están dispuestos a invertir en su país. 


\section{Notas}

1. El análisis de los estos ocho países gobernados por empresarios se desarrolla en el proyecto PICT: Estado, élites y políticas públicas en América Latina 2000-2018 dirigido por la Dra. Inés Nercesian.

2. Vicente Fox en México (2000-2006), Álvaro Uribe (20022010) en Colombia, Elías Antonio Saca (2004-2009) en El Salvador, Sebastián Piñera (2010-2014/2018-) en Chile, Horacio Cartes (2013-2018) en Paraguay, Mauricio Macri (2015-2019) en Argentina, Pedro Pablo Kuczynski (2016-2018) y Michel Temer (2016-2019). En el caso de Brasil, su presidente de facto es un hombre que proviene del mundo de la política, el resto de los casos son gobiernos con presidentes empresarios o con un perfil netamente empresarial. En esta clave puede sumarse el caso de Panamá con los dos gobiernos emblemáticos: Ricardo Martinelli (2009-2014) y Juan Carlos Varela (2014-2019).

3. En El Salvador en 1982 se fue definiendo una situación protodemocrática (Torres Rivas, 2007) en la que convivieron instituciones y prácticas autoritarias con elecciones competitivas. La transición a la democracia y conformación de un sistema bipartidista comenzaron en el marco de la guerra civil.

4. De un total de 5.268.411 personas habilitadas a votar votó un $51,88 \%$ que son 2.733.178. Esto quiere decir que en estas elecciones participaron un 3,4\% menos que en la primera vuelta de 2014 y $9 \%$ menos que la segunda vuelta. Datos disponibles en el sitio del Tribunal Supremo Electoral de El Salvador https://www.tse.gob.sv/

5. Elías Antonio Saca quien fue presidente por GANA entre 2004 y 2009 fue condenado a 10 años de presión en septiembre de 2018 por delitos vinculados al peculado y lavado de dinero. Por malversación de fondos de la obra pública se le solicitó la devolución de \$260 millones de dólares al Estado. Su ex secretario privado Elmer Charlaix también fue condenado.

6. Durante su gestión como alcalde de San Salvador buscó acercarse a los jóvenes proyectando en la plaza central la película de Dragon Ball, se mostró en patineta, promovió competencias de paintball y compartió y creó memes en sus redes sociales.

7. En las elecciones de 2014 el FMLN llevó como candidato a Salvador Sanchéz Cerén que obtuvo un $48.93 \%$ de los votos en primera vuelta ( 1.315 .768 votantes) y un $50,11 \%$ en la segunda vuelta (1.495.815 votos). En 2019 el candidato Hugo Martínez obtuvo 14.41\% de los votos (esto es 389.289 personas votaron en esta oportunidad por el FMLN). Datos recuperados del Tribunal Supremo Electoral de El Salvador https://www.tse.gob.sv/

8. Bukele tiene una cuenta personal de Twitter pero debido al formato de Facebook en lugar de tener una cuenta creó una página, sorteando esta dificultad del requerimiento de tener un seguimiento recíproco.

9. El caso paradigmático para el análisis del vínculo entre redes y política fue el de la campaña de Barack Obama en 2008. Castells (2009) afirma que Obama "aprendió a manejar con maestría las reglas del juego de lo que se ha llamado «la primera campaña en red». Por estas características es por lo que la campaña de Obama constituye un caso paradigmático de la política insurgente en la Era de Internet".

10. El análisis de los primeros cien días de gobierno es un clásico en las ciencias sociales. Es necesario tener en cuenta que estos primeros cien días son el 6\% de un mandato de 
cuatro años y en El Salvador los mandatos son de 6 años por lo que este número se reduce al 4,5\% del mandato. Los cien días se analizan por tener "un significado simbólico y son interpretados muchas veces como un barómetro del poder de un presidente entrante". Generalmente en estos días se define el gabinete, la estructura de ministros, los primeros viajes internacionales de los presidentes, las leyes enviadas del Poder Ejecutivo al Legislativo y las medidas urgentes son algunos de los indicadores. Ver más en https://www.cippec. org/publicacion/los-primeros-100-dias-de-gobierno-implementar-o-planificar/

11. El mes de junio de 2019 es el que mayor cantidad de casos concentra debido a que fue el primer mes de gobierno. En los meses subsiguientes bajó la cantidad de tuits publicados por día y, consecuentemente, bajaron los tuits que se consideraron para el análisis en este artículo.

12. El Instituto Universitario de Opinión Pública (IUDOP) de la Universidad Centroamericana José Simeón Cañas (UCA) de El Salvador en su tradicional evaluación de los primeros cien días del nuevo gobierno, con un muestra nacional de 1,236 personas de 18 años en adelante, expone que pese a que la principal plataforma de transmisión de información sobre las acciones y el quehacer del gobierno de Nayib Bukele es Twitter, un $5.8 \%$ de la población encuestada sostuvo que desconocía esta red social. Y del porcentaje que utiliza redes sociales para informarse, el 81,9\% lo hace con Facebook y sólo el 12,6\% con Twitter.

13. El Gobierno Abierto está basado en principios de transparencia y apertura, participación y colaboración como un paradigma emergente que busca mejorar la administración del Estado vinculada con el desarrollo de nuevas tecnologías. El Salvador es miembro de Alianza de Gobierno Abierto (AGA) desde el 2011 y da seguimiento a las políticas a través de la Secretaría de Participación, Transparencia y Anticorrupción (Ramírez-Alujas, 2011).

\section{Bibliografía}

Ansaldi, W. (2017). Arregladitas como para ir de boda. Nuevo ropaje para las viejas derechas. Theomai 35, primer semestre 2017.

Arismendi, A. (2019). Nayib Bukele en El Salvador. La expresión política de la indignación llega a gobierno. El Salvador: Heinrich-Böll-Stiftung. Disponible en https://sv.boell.org/ sites/default/files/articulonayibbukeleabril2019.pdf

Carlón, M. (2015). Público, privado e íntimo: el caso Chicas bondi y el conflicto entre derecho a la imagen y libertad de expresión en la circulación contemporánea. En César Castro, P. (Org.), Dicotomia público/privado: estamos no caminho certo? (pp. 211-232). Maceió, Brasil: EDUFA.

Cartagena, M. (2019). Nayib Bukele: un presidente "millennial” para El Salvador. Revista Nueva Sociedad, febrero. Disponible en: https://nuso.org/articulo/bukele-salvadorelecciones-corrupcion-progresismo-millenial/

Casco Criccia, B.; Pineda Martínez, J. A. y Quintanilla Clanci, B. (2018). La espectacularización de la política en los medios de comunicación digitales El Salvador. com y la prensa gráfica. com. Caso: Nayib Bukele y su desvinculación del partido FMLN. De septiembre a 
octubre de 2017. (Tesis de licenciatura). Universidad de El Salvador, Facultad de Ciencias y Humanidades, Departamento de Periodismo, San Salvador. Disponible en http://ri.ues. edu.sv/19355/1/14103443.pdf

Castells, M. (2009). Comunicación y poder. Madrid: Alianza Editorial.

Cavarozzi M. y Abal Medina, J. M. (h) (comps.). El asedio a la política. Los partidos latinoamericanos en la era neoliberal. Rosario: Homo Sapiens Ediciones.

Discurso de toma de posesión del presidente Nayib Bukele. (1 de junio de 2019). El Faro [YouTube]. Recuperado el 10/01/2020 de: https://www.youtube.com/watch?v=WQpYFYF8yM

Fraticelli, D. (2019). La circulación contemporánea del sentido. Entrevista a Mario Carlón. Revista Sociedad (39), 288-295.

Giordano, V. (2014). Qué hay de nuevo en las nuevas derechas. Nueva Sociedad 254, diciembre. Disponible en https://nuso.org/articulo/que-hay-de-nuevo-en-las-nuevas-derechas/

Giordano, V. (2019). Hacia una agenda de investigación de las derechas en América Latina en el siglo XXI. Estudios Sociales del Estado. Disponible en http://www.estudiossocialesdelestado.org/index.php/ese/article/view/175

Girón, G. y Marroquín, M. (2019). \#UnaCampañaQueHizoHistoria: Análisis de la comunicación política en Twitter durante las elecciones presidenciales de El Salvador 2019. En Girón, G. y Marroquín, M. TUIT POR TUIT Y VOTO POR VOTO La construcción de perfiles políticos en Twitter en las campañas electorales de \#ElSalvador y \#Guatemala 2019. (pp.16-34). San Salvador: Fundación Heinrich Böll. Disponible en: https://sv.boell. org/sites/default/files/2019-12/web-tuit_por_tuit_voto_por_voto.pdf

La decisión. (15 de octubre de 2019). Nayib Bukele [YouTube]. Recuperado el 9/01/2020 de: https://www.youtube.com/watch? $\mathrm{v}=\mathrm{E} 7 \mathrm{FCWOmDLFo}$

López Eguizábal, F. A. (2018) ¿Cómo convertirse en candidato presidencial en El Salvador, del año 2019, a través de las redes sociales? Un acercamiento entre el votante virtual y físico. En Pérez Serrano, M. J.; Alcolea-Díaz, G. y Nogales-Bocio, A. I. (coords.). (2018). Poder y medios en las sociedades del siglo XXI. (pp.87-112). Sevilla: Egregius Ediciones.

Mainwaring, S. y Scully, T. (1997). La institucionalización de los sistemas de partido en la América Latina. América Latina hoy 16. Disponible en: http://revistas.usal.es/index. php/1130-2887/article/view/2107/2162

Goldwaser Yankelevich, N. (2016). La celebración del bicentenario de la Independencia...un tarifazo de sentimientos políticos. Cuadernos de Coyuntura, GESHAL-IEALC. Disponible en http://coyuntura.sociales.uba.ar/la-celebracion-del-bicentenario-de-laindependenciaun-tarifazo-de-sentimientos-politicos.

Bukele, N. (9 de septiembre de 2019). \#YEstoApenasEmpieza. Nayib Bukele [Posteo en Facebook]. Recuperado el 10/01/2020 de: https://www.facebook.com/nayibbukele/ videos/408319746553890/

Nayib Bukele en Plaza Morazán. La Victoria del Pueblo Salvadoreño. (6 de Febrero de 2019). MBN Digital [YouTube]. Recuperado el 9/01/2020 de: https://www.youtube.com/ watch?v=31YvnhN5fTY.

Nercesian, I; Cassaglia, Ry Grassetti, J. (2018). Élites en América Latina. Ponencia presentada en el marco de la $8^{\circ}$ Conferencia Latinoamericana y Caribeña de Ciencias Sociales. Primer Foro Mundial del Pensamiento Crítico, CLACSO, 22 de noviembre 2018. 
Nercesian, I., y Cassaglia, R. (2019). Radiografía de los gabinetes ministeriales en Brasil y Perú (2016-2018). Un análisis comparativo. Telos, 21 (2), 372-400. Disponible en: https:// www.redalyc.org/articulo.oa?id=99359223008

Rauda Zablah, N. (2019). Nayib Bukele: ¿de millennial rebelde a aliado de Trump? Revista Nueva Sociedad, mayo. Recuperado de: https://nuso.org/articulo/bukele-el-salvadortrump-progresismo-estados-unidos/

Ramírez-Alujas, Á. V. (2011). Gobierno Abierto y Modernización de la Gestión Pública. Tendencias actuales y el (Inevitable) Camino que Viene-Reflexiones Seminales. Revista Enfoques. Ciencia Política y Administración Pública 9 (15), pp. 99-125.

Saravia, C. y Canteros L. S. (4 de febrero, 2019). Quien es Bukele y porqué representa un giro a la derecha en El Salvador. Marcha Noticias. Recuperado el 10/01/2020 de: https://www. marcha.org.ar/quien-es-bukele-y-porque-representa-un-giro-la-derecha-en-el-salvador/

Slimovich, A. (2014). El discurso macrista en Twitter: un análisis sobre la campaña para la reelección del jefe de gobierno de Buenos Aires. Revista de Estudios Políticos y Estratégicos, II (1). Disponible en: http://vtte.utem.cl/wp-content/themes/blogum/ revista_epe/03_Rev_estudios_politicos _estrategicos_vol2_n1_2014_Ana_S_Discurso_Macrista_8-27.pdf

Slimovich, A. (2016). Política y redes sociales en Argentina. El caso de los candidatos presidenciales de 2011 en Twitter. Signo y Pensamiento 35 (68), pp. 86-100. DOI: $10.1177 / 0539018405058216$

Slimovich, A. (2017a). La ruta digital a la presidencia argentina. Un análisis político e hipermediático de los discursos de Mauricio Macri en las redes sociales. Dixit, 26, 24-43). Recuperado: 04/10/2017. En línea: https://revistas.ucu.edu.uy/index.php/revistadixit/ article/view/1321/1369

Slimovich, A. (2017b). Discursos políticos para todos y todas. Reflexiones sobre las redes sociales del presidente argentino. Redes y Trolls. Sociales en debate 12, pp. 37-48. Disponible en: http://www.sociales.uba.ar/wp-content/blogs.dir/219/files/2017/10/ discursospol-ANASLIMOVICHv2.pdf.

Slimovich, A. (2019). La mediatización contemporánea de la política en Instagram. Un análisis desde la circulación hipermediática de los discursos de los candidatos argentinos. Revista Sociedad (39), pp. 31-45.

Verón, E. (1987). La semiosis social. Barcelona: Gedisa.

Verón, E. (1998 [1995]). Mediatización de lo político. Estrategias, actores y construcción de los colectivos. En G. Gauthier, A. Gosselin y J. Mouchon (Comps.). Comunicación y Política, (pp. 220-236). Barcelona: Gedisa.

Verón, E. (2001). El cuerpo de las imágenes. Buenos Aires: Norma.

Verón, E. (2002). Mediatización de la política: discursos en conflicto, cruces y distinciones. Eliseo Verón entrevistado por María Elena Qués y Cecilia Sagol. En de Signis, 2, La Comunicación Política. Transformaciones del espacio público, pp. 367-377. Barcelona: Gedisa. 


\begin{abstract}
Nayib Bukele assumed as president of El Salvador on June 1st, 2019. His victory ended the bipartidism that had prevailed for thirty years in the country between FMLN and ARENA. The youngest Latin American president is now known as a millennial due to his presence in social networks. Bukele constantly uses these tools as a means of political communication. This article aims to investigate the construction of Nayib Bukele's political discourse on his Twitter account during his first hundred days of government. It seeks to figure out how he has built a deideologized and ahistorical discourse around the idea of efficiency, transparency and good administration of the State's resources.
\end{abstract}

Keywords: El Salvador - businessmen - Bukele - political discourse - Twitter.

Resumo: Nayib Bukele assumiu a presidência de El Salvador em 10 de junho de 2019. Com seu triunfo, pude terminar com a alternância bipartidária entre a FMLN e a ARE$\mathrm{NA}$, que começou há trinta anos no país. O presidente mais jovem da América Latina é agora conhecido como millennial devido à sua presença nas redes sociais. Bukele use continuamente essas ferramentas como uma forma de comunicação política. Este artigo tem como objetivo investigar a construção do discurso político de Nayib Bukele em sua conta do Twitter durante os primeiros cem dias de seu governo. Ele procura acompanhar como foi construindo um discurso ahistórico deideologizado sobre a idéia de eficiência, transparência e boa administração dos recursos estatais.

Palavras-chave: El Salvador - empresários - discurso político Bukele - Twitter.

[Las traducciones de los abstracts fueron supervisadas por el autor de cada artículo] 